\title{
DIFFERENCES IN PERINATAL OUTCOMES BETWEEN WOMEN WITH SPONTANEOUS PREGNANCY AND PATIENTS UNDERGOING TO IN VITRO FERTILIZATION IN WOMEN AGED 40 YEARS OR ABOVE
}

Porcel Llaneza, I.; Fernández Blanco, C.; González González, C.; Fernández Fernández, E.; Méndez López, M.I.; Llaneza Coto, A.P.

Department of Gynaecology and Obstetrics, HOSPITAL UNIVERSITARIO CENTRAL DE ASTURIAS, Oviedo, Asturias, Spain

In Western countries, women delay the age of their first pregnancy but postponing pregnancy is a risk for women and pregnancy outcomes.

In women aged 40 years or above, the critical pregnancy rate decreased and assisted reproductive techniques are often recommended.

The objective of this study was to compare pregnancy outcomes in women with spontaneous pregnancy (SP) versus patients undergoing in vitro

Fertilization (IVF) in women aged 40 years or above.
Patients clasified based on type of pregnancy

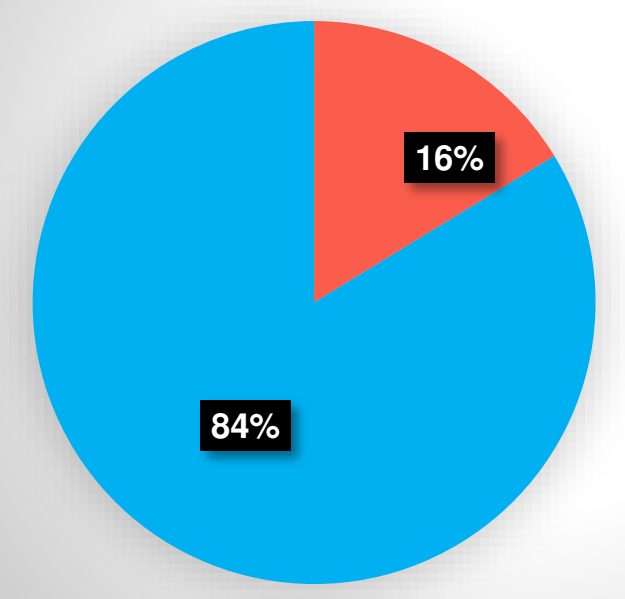

Assisted reproduction technique Spontaneous pregnancy

\section{METHODS}

We retrospectively analysed data of a cohort of $\mathbf{4 7 9}$ women aged $\mathbf{4 0}$ years or above that gave birth in our hospital between January 2015 and December 2016. Multiple pregnancies were not included. Seventy eight women got pregnant after IVF and 401 became pregnant spontaneously.

We assessed:

- Vaginal birth rate

- Risk of pre-eclampsia

- Gestational diabetes rate

- Operative delivery rate

- Post-partum haemorrhage rate

\section{RESULTS}

Vaginal birth rate was similar between SP and IVF $(75.3 \%$ vs. $70.5 \%, p=0.454)$.

Likelihood of assisted vaginal delivery with the help of forceps or vacuum device was lower in SP than in IVF arm $(30.1 \%$ vs $56.4 \%, p<0.001)$.

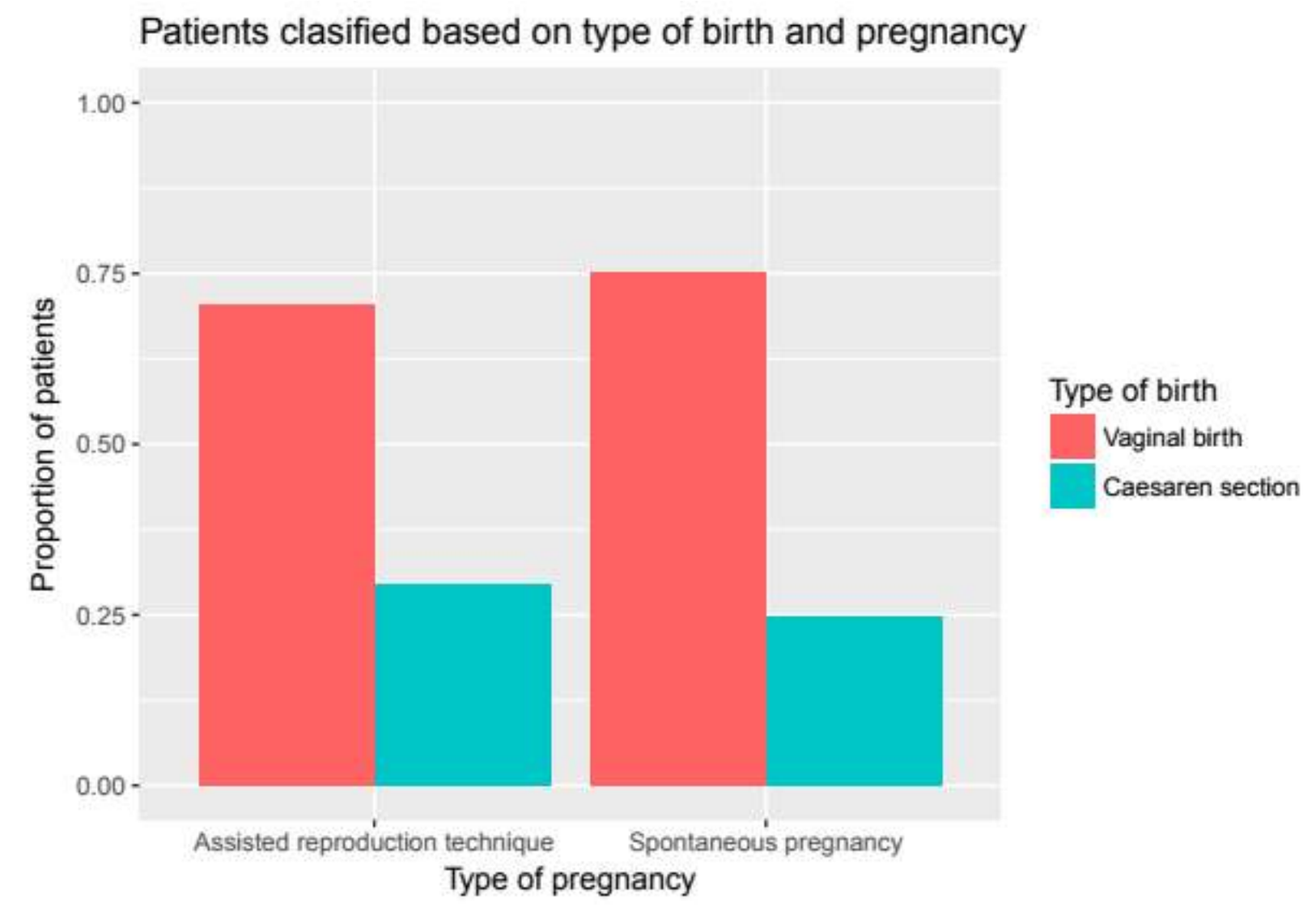

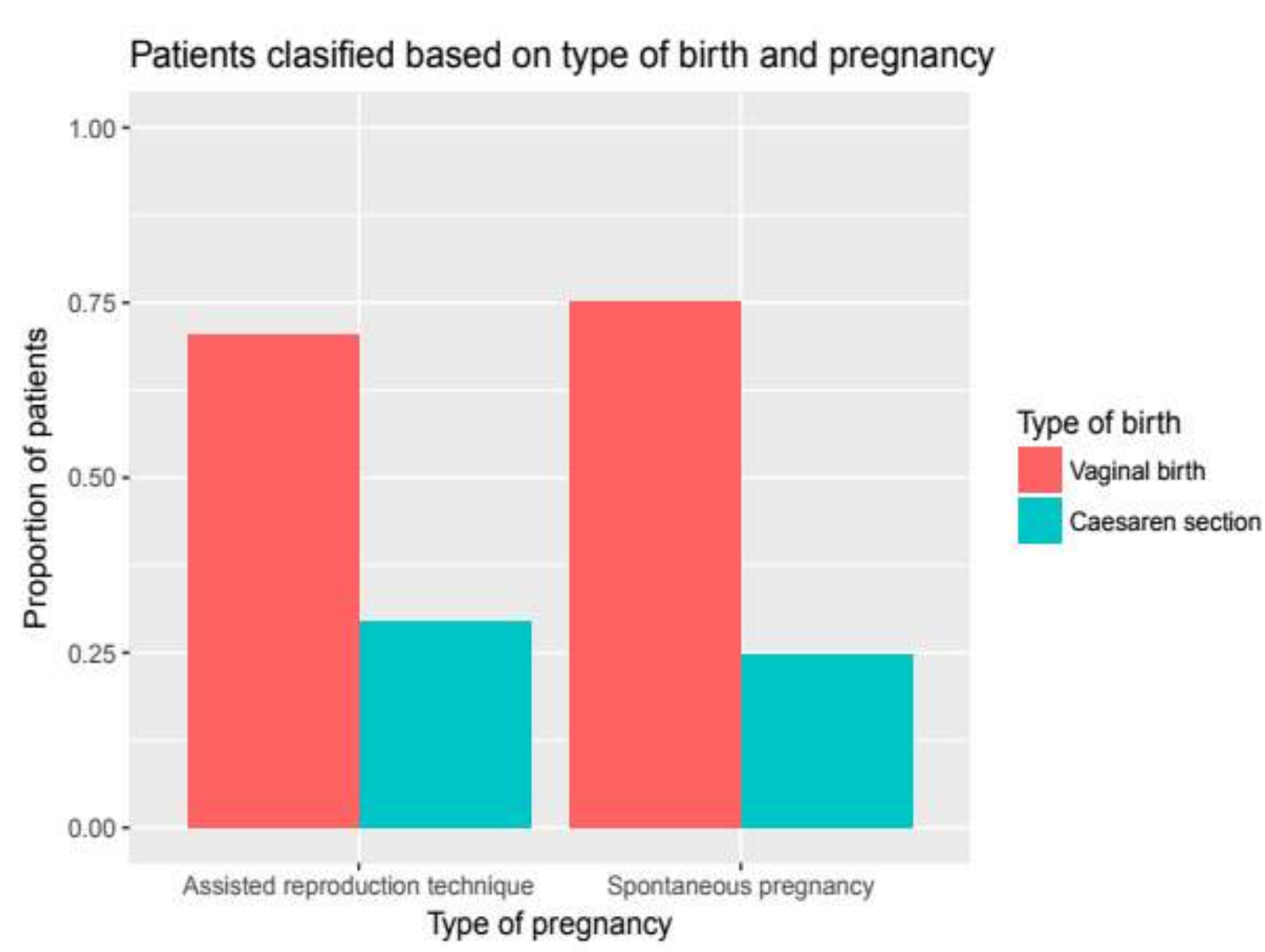

There was not significant difference between both arms of the study in pre-eclampsia, gestational diabetes and postpartum haemorrhage rates.

\section{CONCLUSION}

In our study, perinatal outcomes were no significantly different after IVF tan SP in women aged $\mathbf{4 0}$ years or above and only a higher rate of assisted vaginal deliveries was detected. 